\title{
Design of Legal Chinese English Simultaneous Interpretation System based on PSO Algorithm
}

\author{
Xiling Yang \\ Department of Development and Planning, Chengdu Vocational and Technical College of Industry, \\ Chengdu 610000, China \\ E-mail: hhhyxlyl@163.com
}

Received: August 4, 2021. Revised: December 20, 2021. Accepted: January 11, 2022. Published: January 13, 2022.

\begin{abstract}
Aiming at the phenomenon of "wrong words" and "missing words" in the process of Chinese English legal interpretation, a Chinese English legal simultaneous interpretation system based on PSO algorithm is designed. According to the construction requirements of fuzzy neural network, the optimization results of PSO inertia weight are determined, and then the system model optimization based on PSO algorithm is realized with the help of membership function. On this basis, this paper analyzes the key trigger factors of simultaneous interpretation, and distinguishes the specific differences between consecutive interpretation load and simultaneous interpretation by defining the way of legal Chinese English text transmission effect, so as to realize the smooth application of legal Chinese English simultaneous interpretation system based on PSO algorithm. The results shows that, compared with the consecutive interpretation system, the simultaneous interpretation system can effectively solve all the problems of "wrong words" and "missing words" in the process of legal Chinese English document translation, and effectively guarantee the authenticity of document samples.
\end{abstract}

Keywords-PSO algorithm, Chinese English simultaneous, interpretation system, fuzzy neural network, inertia weight, membership function, trigger factors, translation load.

\section{INTRODUCTION}

$\mathrm{S}_{\mathrm{m}}^{\mathrm{i}}$ imultaneous interpretation is an efficient translation method. The average time interval between the original text and the target text is 3 to 4 seconds, with a maximum of 10 seconds. Therefore, it can ensure that the speaker makes a coherent speech without affecting or interrupting the speaker's thinking, which is conducive to the audience's understanding of the full text of the speech. During the meeting, the simultaneous interpreter will sit in a soundproof small room (commonly known as "box") and use professional equipment to synchronously translate the content he hears from the headset into the target language and output it through the microphone. Participants who need simultaneous interpretation service can adjust their language channel through the receiving device and receive it from the headset [1], [2]. However, in the process of simultaneous interpretation, some proper terms related to law, if the simultaneous interpreter is not the corresponding legal translation specialty, it is very easy to lead to word errors and word omissions. Therefore, it is urgent to study an efficient legal Chinese-English simultaneous interpretation system.

Almutairi et al. [3] pointed out that English has become a global language in today's world. It is also widely used in non-native English speaking communities. However, due to the lack of resources, such as teaching literature and skilled English teachers, English teaching has become inefficient. Educational institutions and non-native English students are affected by these problems. In order to effectively solve the above problems, the literature puts forward an artificial intelligence based English learning framework. The proposed artificial intelligence based framework combines previously proposed algorithms and other newly developed technologies to enhance language learning. The framework enables individual learners to interact with the framework to improve and strengthen the English learning process. In addition, the proposed system can effectively cope with the lack of educational institutions providing English learning courses Resources. Machine translation has become an irreplaceable application in mobile phone use [4]. However, the current mainstream neural machine translation model depends on increasing the number of parameters to achieve better performance, which is not suitable for mobile phones. In this paper, the paper uses the shallow syntax of the target language (e.g., POS tag) to improve neural machine translation (NMT) In particular, compared with other complex machine translation models, the model in this paper needs less parameters and running time, which makes mobile applications possible. Specifically, this paper proposes three RNN based NMT decoding models (independent decoder, gate shared decoder and fully shared 
decoder) to jointly predict the target word and POS tag sequence. Experiments on Chinese-English and German-English translation tasks show that the fully shared decoder can achieve the best performance.

Although the above methods realize simultaneous interpretation or Chinese-English translation, the translation accuracy of legal proper nouns is unknown. In order to avoid the phenomenon of "wrong words" and "missing words", this paper optimizes its design. Particle swarm optimization (PSO) simulates the group behavior of insects, animals, birds and fish. These groups look for food in a cooperative way [5]. Each member changes his search mode by learning his own experience and the experience of other members. This model is used to simulate the behavior of birds and is also a particle swarm optimization algorithm [6], [7]. The simplest model is that each bird is represented as a point in the rectangular coordinate system, and an initial speed and initial position are randomly assigned to them. Each step of the program runs according to the "nearest neighbor speed matching" rule, and the speeds of all points will soon become the same.

\section{SYSTEM MODEL OPTIMIZATION BASED ON PSO ALGORITHM}

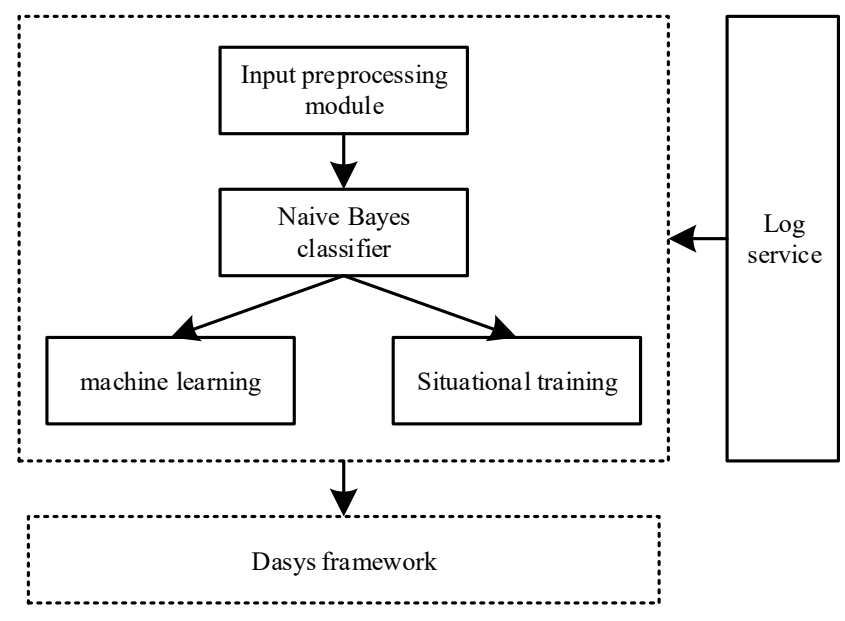

Figure 1. Framework of legal Chinese English simultaneous interpretation system

From the analysis of the design objectives of the legal Chinese-English simultaneous interpretation system, the overall architecture is divided into: preprocessing module, naive Bayesian classification module, machine learning module, resource training module, dasyx framework module and log service module. The overall architecture is shown in Figure 1.

The main function of dasyx framework in legal Chinese-English simultaneous interpretation system is to provide distributed parallel computing services for the system and ensure that the resource base can run efficiently and stably.

From the analysis of the application objectives of legal
Chinese-English simultaneous interpretation system, the functional architecture of legal Chinese-English simultaneous interpretation system is mainly composed of machine learning system, resource training set, legal English interpretation word segmentation system and naive Bayesian classifier. The operation process is as follows: after the legal Chinese-English simultaneous interpretation system obtains the translation to be transmitted, it first performs word segmentation on the text information through the legal English interpretation word segmentation system, filters out the useless information, and transmits the results to the naive Bayesian classifier after word segmentation; The classifier calculates the probability value of text information through the text training set, classifies the results in the order from large to small, and matches the resource type to which the maximum probability value belongs; The matching result set is combined with the initial training set through the machine learning system to continuously optimize and update the word structure and feature weight of the text, so as to ensure the accuracy of interpretation.

Considering that the existing Chinese-English simultaneous interpretation system is relatively mature, this study only focuses on the translation accuracy of the software part, and uses PSO algorithm to optimize it.

\section{A. Fuzzy neural network}

Fuzzy neural network is the product of combining fuzzy theory with neural network. It combines the advantages of neural network and fuzzy logic, and combines learning, adaptive, association, recognition and fuzzy information processing. In the fuzzy neural network, neural network technology and fuzzy technology are effectively integrated, and the concepts of rule reasoning and fuzzification are applied in the nodes. The combination of this knowledge greatly improves the transparency of fuzzy neural network [8], [9]. The strong ability of explanation and reasoning is one of the characteristics of fuzzy neural network. At the same time, the network no longer relies heavily on the subjective opinions of experts, and its self-adaptive ability is greatly improved. The fuzzy neural network is the process of fuzzifying the sample. In the process of processing, it should be transformed into regular form. The mapping relationship between input and output is expressed by membership function. Fuzzifying neuron is a kind of neuron that can quantify or standardize the observed value or input value. In short, the fuzzy neuron function of PSO algorithm is to transform the input value into fuzzy output value [10], [11]. It is assumed that $s_{0}$ represents the minimum transparency coefficient of PSO parameters, $s_{n}$ represents the maximum transparency coefficient of PSO parameters, and $n$ represents the fuzzification degree of PSO parameters. Combined with the above physical quantities, the fuzzy neural network based on PSO algorithm can be defined as: 


$$
S=\sum_{s_{n}, n=0}^{s_{n}} \frac{w_{1} w_{s_{n}}+\bar{Y}}{n^{2}}
$$

In the formula, $w_{1}$ and $w_{n}$ represent the first and $n$-th PSO sample neuron parameters respectively, and $\bar{Y}$ represents the mean value of the input quantity of the PSO sample data.

\section{B. PSO inertia weight optimization}

The degree to which a particle maintains its original velocity depends on the inertia weight. With the change of inertia weight, the degree of trust in its own motion state also changes. In the early research of particle swarm optimization algorithm, the values of inertia weight and learning factor are fixed, so the maximum speed of particles must be adjusted to ensure that the particles fly in a certain speed range. The selection of inertia weight in the algorithm is very important. Because the selection of different inertia weight values plays a decisive role in the convergence speed of the algorithm, the convergence speed of the algorithm can be improved by adjusting the inertia weight [12], [13]. In the traditional PSO algorithm, the selection of inertia weight decreases linearly, but the particle flies to the optimal position in the current population at a higher speed in the process of motion. When the particle flies near the global optimal position, because the flight speed of the particle is still very fast, it is likely to miss the global optimal position, thus reducing the convergence accuracy. The traditional particle swarm optimization algorithm may not search every corner of the whole space in the optimization process, so it is very likely to fall into the local optimal solution, so it can not converge to the global optimal solution to a certain extent. Supposing $\Delta T$ represents the unit processing time of PSO algorithm, $g_{1}$ and $g_{2}$ represent two different data information indexes respectively, and the simultaneous Formula (1) can express the optimization result of PSO inertia weight as follows:

$$
D=\sum_{i=1}^{e_{\max }} S \cdot\left|g_{2}-g_{1}\right| / \Delta T_{i}
$$

In the formula, $i$ represents the lower limit weight parameter of PSO inertial particle, $e_{\max }$ represents the upper limit weight parameter of PSO inertial particle.

\section{Membership function}

In fuzzy mathematics, the concept of membership function is introduced, through which the membership degree of each element to the fuzzy set is expressed. The function is an intuitive expression of fuzziness and fuzziness, with which the fuzzy set can be quantified [14]. Establishing membership function correctly is the key to making fuzzy set express fuzzy set properly, and it is also the basis of analyzing and processing fuzzy information by using precise mathematical method.

There are many things to pay attention to in determining membership function of fuzzy neural network:
(1) The membership function of fuzzy neural network module can be determined by the experience accumulated in practical operation. We can also use the probability theory in mathematics to deal with the data, and use the fuzzy mathematics to determine the membership function.

(2) The membership function of fuzzy neural network is determined by the trial value theory of fuzzy mathematics.

(3) To determine a good membership function, we need to judge whether it is in line with the actual situation, not only for the size of a single membership value, but also comprehensively consider each angle, so as to judge the degree of an element to the set [15], [16]. $x$ is the initial membership condition in PSO algorithm, and $c$ is the actual membership condition in PSO algorithm. According to the simultaneous Formula (2), the membership function based on PSO algorithm can be defined as:

$$
Z=\frac{D}{1+\left(\frac{x-c}{a}\right)^{2 b}}
$$

In the formula, $a$ represents the evaluation coefficient for a single PSO membership index, and $b$ represents the power term evaluation index.

\section{The CONSTRUCTION OF LEGAl CHINESE ENGLISH SIMULTANEOUS INTERPRETATION SYSTEM}

\section{A. Trigger factors of simultaneous interpretation}

The main trigger factors of legal simultaneous interpretation are as follows:

(1) Information intensive, such as fast speaking.

(2) External factors, such as sudden drop of sound quality in the interpreter's headphones, noise, or other factors that interfere with the process of listening and analysis. All professional words appear, but the interpreter is not prepared, so it is necessary to reorganize the information in the target language. Or too strong accent, grammatical and lexical errors, increase the interpreter's listening and analysis load.

(3) A proper noun consisting of several words, or the interpreter does not know the corresponding expression of the noun in the target language, greatly increases the memory burden of the interpreter.

(4) The semantic differences between the source language and the target language are so great that the interpreter has to store a lot of information in his brain in order to reorganize the information, especially in German, French and Japanese English translation [17].

(5) Numbers, abbreviations.

These problem trigger points do not necessarily trigger problems. For example, if a long string of nouns appears at the end of a sentence and there is a long pause after that, the listening and analysis load will disappear. After the speaker finishes the noun, the interpreter can focus on memory and production.

Simultaneous interpretation is synchronic while consecutive interpretation is diachronic. Simultaneous interpreters only need to mobilize their instantaneous 
memory, while consecutive interpreters need to mobilize their short-term and long-term memory. It is difficult for simultaneous interpreters to achieve ideal meaning translation in a way completely independent of language equivalence on the basis of breaking away from the shell of the original words. There are always some semantic equivalence formed by mechanical code translation in the translation. Consecutive interpreters have enough time to fully recognize and understand the textual meaning of a whole speech, so it is easy to discard the shell of the source language words in the target language and focus on reproducing the meaning of the source language speech with the target language words as the shell [18]. The job performance of interpreters is measured by the quality of the translation, which depends on the processing ability of the translation in different aspects such as listening comprehension, speech production and information memory. Simultaneous interpreting is a kind of activity that translates one language into another in a limited time. As interpreters often encounter difficulties in information redundancy in practice. In simultaneous interpretation, the degree of redundancy dealt with by interpreters is directly related to the efficiency and quality of their translation. Therefore, we should face and understand the interpreters' performance in a more scientific and objective manner. Including their mistakes.

\section{B. Definition of transmission effect}

Simultaneous interpretation and consecutive interpretation have different pressures at different levels. On the psychological level, consecutive interpreters and the audience face go to face and receive more attention, so they are under greater pressure. Simultaneous interpreters do not need to face the audience directly, and the pressure comes more from how to process information quickly. From the perspective of skills, consecutive interpretation is more about note taking and information reorganization, while simultaneous interpretation requires higher coordination ability of interpreters. Therefore, in terms of training skills and mastering methods, the two kinds of translation methods are different, and it can not be generally considered that consecutive interpretation is easy for simultaneous interpretation [19]. At the same time, legal interpreters only need to mobilize immediate memory, while continuous interpreters need to mobilize their short and long - term memories. And some legal interpreters find it difficult to realize the ideal meaning translation on the basis of a way completely independent of language equivalence. There is always some semantic equivalence formed by mechanical code translation in the translation. Consecutive interpreters have enough time to fully recognize and understand the discourse meaning of a whole speech, so it is easy to discard the shell of the source language words in the target language and focus on reproducing the meaning of the source language speech with the target language words as the shell.

The trigger factors for the first stage of the cross are the same as those of simultaneous interpreting. The main difference between the two translation methods lies in note taking. Note taking, to a certain extent, is a "mechanical movement", so it takes more time than speech production, resulting in the interpreter lagging behind the speaker, thus increasing the memory load, which in turn reduces the energy available for listening and analysis. However, some people think that taking notes takes less time than simultaneous interpreting, because notes only need to note the information of words or paragraphs, and in speech output, a complete sentence is needed [20], [21]. In addition, the interpreter writes down part of the information and stores the rest in memory. The interpreter's performance is measured by the quality of the target language produced, which in turn depends on the distribution of their processing ability in different aspects of interpretation, such as listening comprehension, speech production and information memory. Simultaneous interpreting is a kind of translation practice that is expressed in one language and expressed in another language at the speed of almost simultaneous expression with the speaker. Due to the differences and characteristics of the two languages, the phenomenon of redundancy occurs in the process of interpretation. In order to improve the effect and quality of the same communication, the translator needs to have good psychological quality and language ability. This includes the ability to deal with redundant components

\section{Consecutive interpreting load}

Getting more information and more time to think while we listening to the speaker. But this strategy may lead to the increase of short-term memory load. When an interpreter can't understand a professional noun, name or number well, he can use his knowledge of the language, subject or context to reorganize the information. This process is an integral part of the understanding of daily conversation, but in simultaneous interpretation, it refers to a conscious effort process rather than subconscious understanding in daily life. However, this strategy may lead to saturation effect [22]. The interpreter may understand a certain word, but he does not know the corresponding said in the source language. In this case, the word can be used to explain. However, this strategy also has some disadvantages. One is that it needs a lot of time and processing ability, the other is that it may divert the audience's attention and make the audience lose confidence in the interpreter, thus affecting the role of the speaker.

Chinese English Continuous translation of law, also known as impromptu translation, refers to a kind of translation practice in which the interpreter and other speakers, after speaking part or all of the original language, reexpressed the thoughts and feelings expressed by the speaker to the audience orally in the target language. The so-called simultaneous interpretation refers to a kind of translation practice in which the thoughts and feelings expressed in another language are verbally reexpressed in one language at almost the same speed as the speaker. Simultaneous interpretation and consecutive interpretation have different pressures at different levels [23]. On the 
psychological level, consecutive interpreters and the audience go face to face and receive more attention, so they are under greater pressure. Simultaneous interpreters do not need to face the audience directly, and the pressure comes more from how to process information quickly. From the perspective of skills, consecutive interpretation is more about note taking and information reorganization, while simultaneous interpretation requires higher coordination ability of interpreters. Therefore, in terms of training skills and mastering methods, the two kinds of translation methods are different, so it cannot be generally considered that consecutive interpretation is easy than simultaneous interpretation.

\section{APPLICATION TEST}

Considering that if there is too much missing information in the translation, it will affect the analysis results. First of all, the translator's translation is compared with the original text, and only the comments without missing information are selected for analysis, including the translation of source language 1 and the translation of source language 2 . In the selection of translators, in the process of application test, the translators selected in this paper are all student interpreters with Chinese as their mother tongue and English as their first foreign language. The specific test process is as follows:

Firstly, the above parameters in the translated text and the original text are counted, and then the parameters in the translated text are compared with the corresponding parameters in the original text by chi square test to determine whether oral and written deviation occurs and the direction of deviation. The specific analysis methods are as follows:

The parameters of oral and written in source language one and source language one are counted respectively. The parameters in the translation and the original text are compared. According to the differences of the parameters, the tendency of oral and written deviation (that is, the possible direction of deviation) is judged. Then, through chi square test, the parameters in each translation and the original text are compared to judge whether there are significant differences between the oral and written features of the target language and the source language; through chi square test, we compare the parameters in the original and the translated versions to see if there are significant differences. According to the deviation trend and chi square analysis results, we can judge whether the oral and written nature of the text is deviated and the direction of the deviation. The specific data and analysis results are shown in Table 1, Table 2 and Table 3 , which correspond to translation 1 , translation 2 and translation 3 respectively.

Table 1. Simultaneous interpretation results of legal translation 1

\begin{tabular}{|c|c|c|c|c|c|}
\hline Feature & $\begin{array}{l}\text { Sourc } \\
\mathrm{e} \\
\text { langu } \\
\text { age }\end{array}$ & $\begin{array}{c}\text { Targe } \\
\mathrm{t} \\
\text { langu } \\
\text { age }\end{array}$ & $\begin{array}{l}\text { Devia } \\
\text { tion } \\
\text { trend }\end{array}$ & $\begin{array}{c}\text { Chi-sq } \\
\text { uare } \\
\text { value }\end{array}$ & $\begin{array}{c}\text { Signifi } \\
\text { cant } \\
\text { level }\end{array}$ \\
\hline Correct & 13 & 1 & - & 10.286 & 0.001 \\
\hline Redundancy & 15 & 3 & - & 8.000 & 0.005 \\
\hline
\end{tabular}

\begin{tabular}{cccccc}
\hline $\begin{array}{c}\text { Mood } \\
\text { Auxiliary }\end{array}$ & 2 & 0 & - & --- & --- \\
$\begin{array}{c}\text { Coordinating } \\
\text { conjunctions }\end{array}$ & 42 & 15 & - & 12.789 & 0.000 \\
$\quad \begin{array}{c}\text { Broken } \\
\text { sentence }\end{array}$ & 9 & 3 & - & 3.000 & 0.083 \\
$\begin{array}{c}\text { structure } \\
\text { Parenthesis }\end{array}$ & 13 & 6 & - & 2.579 & 0.108 \\
$\begin{array}{c}\text { Grammatical } \\
\text { errors }\end{array}$ & 21 & 1 & - & 18.182 & 0.000 \\
$\begin{array}{c}\text { Nominalizati } \\
\text { on }\left(\chi^{2}\right)\end{array}$ & 5 & 10 & - & 1.667 & 0.197 \\
$\begin{array}{c}\text { Subordinatin } \\
\text { g conjunction }\end{array}$ & 2 & 2 & - & 0.000 & 1.000 \\
$\quad(p)$ & & & & & \\
\hline
\end{tabular}

Table 2. Simultaneous interpretation results of legal translation 2

\begin{tabular}{|c|c|c|c|c|c|}
\hline Feature & $\begin{array}{l}\text { Sourc } \\
\mathrm{e} \\
\text { langu } \\
\text { age }\end{array}$ & $\begin{array}{l}\text { Targe } \\
\mathrm{t} \\
\text { langu } \\
\text { age }\end{array}$ & $\begin{array}{l}\text { Devia } \\
\text { tion } \\
\text { trend }\end{array}$ & $\begin{array}{l}\text { Chi-sq } \\
\text { uare } \\
\text { value }\end{array}$ & $\begin{array}{l}\text { Signifi } \\
\text { cant } \\
\text { level }\end{array}$ \\
\hline Correct & 13 & 4 & - & 4.765 & 0.029 \\
\hline Redundancy & 15 & 6 & - & 3.857 & 0.050 \\
\hline $\begin{array}{c}\text { Mood } \\
\text { Auxiliary }\end{array}$ & 2 & 0 & - & --- & --- \\
\hline $\begin{array}{l}\text { Coordinating } \\
\text { conjunctions }\end{array}$ & 42 & 13 & - & 15.291 & 0.000 \\
\hline $\begin{array}{l}\text { Broken } \\
\text { sentence } \\
\text { structure }\end{array}$ & 9 & 2 & - & 4.455 & 0.035 \\
\hline Parenthesis & 13 & 12 & - & 0.040 & 0.841 \\
\hline $\begin{array}{l}\text { Grammatical } \\
\text { errors }\end{array}$ & 21 & 2 & - & 15.696 & 0.000 \\
\hline $\begin{array}{l}\text { Nominalizati } \\
\text { on }\left(\chi^{2}\right)\end{array}$ & 5 & 6 & - & 0.091 & 0.763 \\
\hline $\begin{array}{l}\text { Subordinatin } \\
\text { g conjunction } \\
(p)\end{array}$ & 2 & 6 & - & 2.000 & 0.157 \\
\hline
\end{tabular}

The chi square test was used to compare all the parameters of translation 1 with those of the original text, shows that $\chi^{2}=24.236, d f=8$ and $p<0.005$ it means that there are significant differences in the oral and written quality between the two versions.

Table 1 lists the changes of oral and written parameters. It can be seen that the frequency of subordinate conjunctions in the original and the translation is the same, which does not reflect any tendency of oral and written deviation. The other oral parameters were smaller and the written parameters increased, indicating that the oral nature of the texts after simultaneous interpreting had a tendency to weaken.

Chi square test showed that correction, redundant wordiness, modal particles, coordinate conjunctions and grammatical errors changed significantly $(p<0.05)$.

Thus, in this case, the oral speech quality of simultaneous interpreting is significantly reduced, mainly in corrections, redundancy, modal auxiliaries, coordinate conjunction and 
grammatical errors.

The chi square test was used to compare all the parameters of translation 2 with those of the original text, shows that $\chi^{2}=22.915, d f=8$ and $p<0.005$ it means that there are significant differences in the oral and written quality between the two versions.

Chi square test showed that correction, redundant wordiness, modal particles, coordinate conjunctions and grammatical errors changed significantly $(p<0.05)$.

Thus, in this case, simultaneous interpreting has greatly weakened the textual nature of speech, mainly in correction, redundancy, wording, modal auxiliaries, coordinate conjunction, sentence structure fragmentation and grammatical errors.

Table 3. Simultaneous interpretation results of legal translation 3

\begin{tabular}{|c|c|c|c|c|c|}
\hline Feature & $\begin{array}{l}\text { Sourc } \\
\mathrm{e} \\
\text { langua } \\
\text { ge }\end{array}$ & $\begin{array}{c}\text { Targe } \\
\mathrm{t} \\
\text { langu } \\
\text { age }\end{array}$ & $\begin{array}{l}\text { Devi } \\
\text { ation } \\
\text { trend }\end{array}$ & $\begin{array}{l}\text { Chi-sq } \\
\text { uare } \\
\text { value }\end{array}$ & $\begin{array}{c}\text { Signifi } \\
\text { cant } \\
\text { level }\end{array}$ \\
\hline Correct & 13 & 1 & - & 10.286 & 0.001 \\
\hline Redundancy & 15 & 2 & - & 9.941 & 0.002 \\
\hline $\begin{array}{c}\text { Mood } \\
\text { Auxiliary }\end{array}$ & 2 & 0 & - & --- & --- \\
\hline $\begin{array}{l}\text { Coordinating } \\
\text { conjunctions }\end{array}$ & 42 & 15 & - & 12.789 & 0.000 \\
\hline $\begin{array}{l}\text { Broken } \\
\text { sentence } \\
\text { structure }\end{array}$ & 9 & 4 & - & 1.923 & 0.166 \\
\hline Parenthesis & 13 & 13 & - & 0.040 & 1.000 \\
\hline $\begin{array}{c}\text { Grammatical } \\
\text { errors }\end{array}$ & 21 & 2 & - & 15.696 & 0.000 \\
\hline $\begin{array}{l}\text { Nominalizati } \\
\text { on }\left(\chi^{2}\right)\end{array}$ & 5 & 6 & - & 0.091 & 0.763 \\
\hline $\begin{array}{l}\text { Subordinatin } \\
\text { g conjunction } \\
(p)\end{array}$ & 2 & 3 & - & 0.200 & 0.655 \\
\hline $\begin{array}{l}\text { Subordinatin } \\
\text { g conjunction } \\
(p)\end{array}$ & 2 & 6 & - & 2.000 & 0.157 \\
\hline
\end{tabular}

The chi square test was used to compare all the parameters of translation 3 with those of the original text, shows that $\chi^{2}=23.317, d f=8$ and $p<0.005$ it means that there are significant differences in the oral and written quality between the two versions.

Table 3 lists the changes of oral and written parameters. It can be seen that the frequency of parenthesis in the original text is the same as that in the translation, which does not reflect any tendency of oral and written deviation. The changes of other parameters all showed that the spoken language of simultaneous interpreting decreased.

Chi square test showed that correction, redundant wordiness, modal particles, coordinate conjunctions and grammatical errors changed significantly $(p<0.05)$.

A training platform with strong performance needs to meet the online training of thousands of people at the same time. Take CPU occupancy and platform response time as the performance indicators to measure the stability of the platform, and test the stability of the platform in this paper. The results are shown in Figure 2.

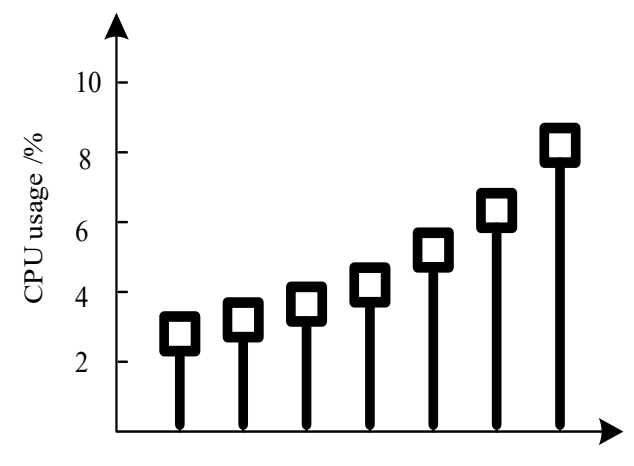

$0 \quad 600120018002400300036004200$

Number of concurrent users / piece

(a) Platform CPU usage

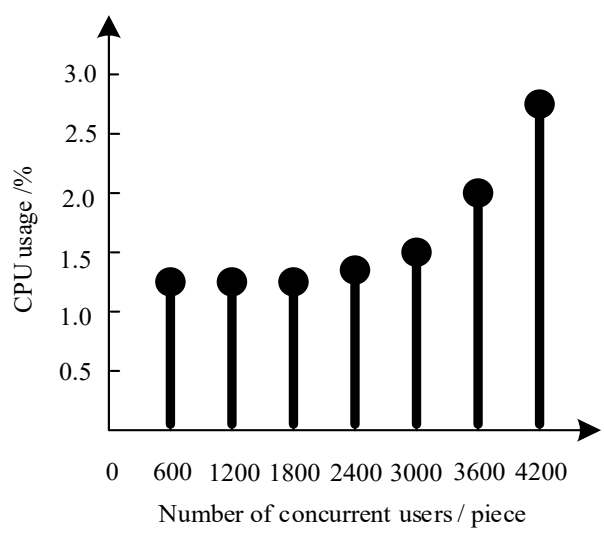

(b) Platform response time

Figure 2. Platform stability test results

By analyzing Figure 2 (a), it can be seen that the CPU occupancy of this platform increases with the increase of the number of concurrent users, and shows a gentle upward trend with a small increase. When 4200 people use this platform at the same time, the CPU occupancy is only $9 \%$; According to the analysis of Figure 2 (b), the platform response time is directly proportional to the number of concurrent users. When the number of concurrent users is between 600 and 3000, the upward trend of the platform response time is not obvious. When the number of concurrent users exceeds 3000 , the platform response time increases rapidly. When the number of concurrent users is 4200 , the platform response time is only $2.8 \mathrm{~s}$. This training platform has low CPU occupancy, short platform response time and high platform stability.

\section{DISCUSSION}

In addition to modern equipment, simultaneous interpreting requires simultaneous interpretation and occupation training and the following qualities:

(1) Solid bilingual and oral expression: simultaneous 
interpreting should be a language sensitive person. Strong ability to catch language (foreign language and mother tongue). Be interested in new things and remember some new words and expressions in time. There is no time for simultaneous interpreting to work. Therefore, the accumulation of language at ordinary times is important for creating a successful interpreter. In addition to having a solid bilingual ability, simultaneous interpreting personnel also need to have strong oral expression. In order to keep up with speakers, the speed of simultaneous interpreting is generally around 250 words/minute, while the average speaker's speed is about 150 words. Therefore, simultaneous interpreting speak logically having teeth and having substance in speech. Enunciation is clear, pronunciation and intonation are smooth and neat.

(2) Master encyclopedic knowledge: no two of the simultaneous interpreting translators need to be translated. The content of the translation involves a wide range of topics, including all aspects of global development, such as politics, economy, culture, science and technology, population, environment, health, war and peace. Therefore, simultaneous interpreting is required to "know astronomy and know geography". The more familiar subjects are, the higher the quality of simultaneous interpreting is.

(3) Good psychological quality: translators who are new to the translation world often feel that they are "flustered and tight mouthed" during translation, and the familiar content may be a mess. This is mainly caused by poor psychological quality. Simultaneous interpreting interpreters should have good psychological quality. We should be able to "deal with chaos and be emotionally stable". A simultaneous interpreting interpreter must have strong emotional control and be calm in any situation. If the mood is unstable, there will be stage fright, which will affect understanding and translation quality, and the translator will even have the phenomenon of "brain blank". To maintain good psychological quality, we mainly rely on the usual building. If we lay a solid foundation, we will naturally have self-confidence. With self-confidence, our psychological state will be easy to adjust.

(4) Have a strong desire for knowledge: the skills of simultaneous interpretation include three sections: (1) interpretation skills; (2) Professional knowledge; (3) Language time. The latter two of the three editions require translators to constantly learn and accumulate. If the translator lacks interest in the acquisition of new knowledge, it is difficult to cope with the changing translation themes.

(5) Teamwork spirit: the simultaneous interpretation of professional words is usually done in groups of 2-3 people, one for about 20 minutes, and the other takes turns. This requires that the work of simultaneous interpreting requires not only the good quality of the interpreter, but also a harmonious whole between the interpreters. Cooperate with each other and do a good job in the whole translation work. Teamwork is reflected in the following aspects: (1) division of labor: it can be divided according to the advantages of each translator, so that we can learn from each other's strengths and make up for our weaknesses in the process of translation; (2) Preparation before translation: prepare separately, and then communicate with each other to save time and improve efficiency; (3) The interpreter at the wheel rest shall help the online interpreter to do auxiliary work, including taking notes, removing interference, monitoring equipment, etc. In short, in the process of simultaneous interpreting, interpreters should be considerate and supportive.

\section{CONCLUSION}

In the process of interpretation, the interpreter should not only fully activate the relevant language and cultural schemata, but also properly use various interpretation strategies, so as to successfully convert the source language information into the target language information in time and accurately, so as to achieve the purpose of coordinated communication.

Therefore, this paper studies the translation deviation in legal simultaneous interpretation. Firstly, the corpus is collected in the simulated situation, and then the qualitative and quantitative research methods are used to prove that simultaneous interpretation will lead to discourse deviation and written deviation. Compared with previous studies, it expands the scale of corpus and adopts the combination of qualitative analysis and quantitative analysis to make the research results more reliable.

Of course, there are also deficiencies in the research. Limited by conditions, the translators selected in this study are Chinese as their mother tongue and English as their first foreign language, and they are student interpreters, lacking diversity. In future research, if the conditions are met, we can consider increasing the diversity of interpreters, including not only native Chinese interpreters, but also native English interpreters; It includes not only student interpreters, but also professional interpreters.

\section{REFERENCES}

[1] R. Hemalatha, R. Prakash and C. Sivapragash, "Analysis on energy consumption in smart grid WSN using path operator calculus centrality based HSA-PSO algorithm", Soft Computing, vol. 24, no. 14, pp. 10771-10783, 2020.

[2] N. Gupta, J. Saxena and K.S. Bhatia, "Optimized metamaterial-loaded fractal antenna using modified hybrid BF-PSO algorithm", Neural Computing and Applications, vol. 32, no. 11, pp. 7153-7169, 2020.

[3] A. Almutairi, A. Gegov, M. Adda and F. Arabikhan, "Conceptual artificial intelligence framework to improving English as second language", WSEAS Transactions on Advances in Engineering Education, vol. 17, pp. 87-91, 2020.

[4] P. Ganesh, B. S. Rawal, A. Peter and A. Giri, "POS-tagging based neural machine translation system for European languages using transformers", WSEAS Transactions on Information Science and Applications, vol. 18, pp. 26-33, 2021. 
[5] X. Feng, Z. Feng, W. Zhao, B. Qin and T. Liu, "Enhanced neural machine translation by joint decoding with word and pos-tagging sequences", Mobile Networks and Applications, vol. 25, no. 7553, 2020.

[6] M. M. Alizadeh and S. E. Hosseini, "Pattern synthesize of a cylindrical conformal array antenna by PSO algorithm", International Journal of RF and Microwave Computer-Aided Engineering, vol. 30, no. 4, pp. e22137.1-e22137.8, 2020.

[7] S. Singh, P. Chauhan and N. J. Singh, "Capacity optimization of grid connected solar/fuel cell energy system using hybrid ABC-PSO algorithm", International Journal of Hydrogen Energy, vol. 45, no. 16, pp. 10070-10088, 2020.

[8] G. Boudechiche, M. Sarra, O. Aissa, J.-P. Gaubert, B. Benlahbib and A. Lashab, "Anti-windup FOPID-based DPC for SAPF interconnected to a PV system tuned using PSO algorithm", European Journal of Electrical Engineering, vol. 22, no. 4-5, pp. 313-324, 2020.

[9] M. Ren, X. Huang, X. Zhu and L. Shao, "Optimized PSO algorithm based on the simplicial algorithm of fixed point theory", Applied Intelligence, vol. 50, no. 7, pp. 2009-2024, 2020.

[10] S. M. Ahmadkhah, R. P. R. Hasanzadeh and M. Papaelias, "Arbitrary crack depth profiling through ACFM data using type-2 fuzzy logic and PSO algorithm", IEEE Transactions on Magnetics Mag, vol. 55, no. 2, pp. 1-10, 2019.

[11] L. M. Cruz, D. L. Alvarez, A. S. Al-Sumait, S. Rivera, "Load curtailment optimization using the PSO algorithm for enhancing the reliability of distribution networks", Energies, vol. 13, no. 12, pp. 3236-3251, 2020.

[12] C. Amarendra and K. H. Reddy, "Performance analysis intelligent-based advanced PSO algorithm and testing of real-time matrix converter electrical system", Soft Computing, vol. 24, no. 18, pp. 14209-14220, 2020.

[13] S. Prithi and S. Sumathi, "LD-2FA-PSO: A novel learning dynamic deterministic finite automata with PSO algorithm for secured energy efficient routing in wireless sensor network", Ad Hoc Networks, vol. 97, pp. 102024.1-102024.14, 2020.

[14] B. Hussain, A. Khan, N. Javaid, Q. Hasan, S. A. Malik, O. Ahmad, A. Dar and A. Kazmi, "A Weighted-Sum PSO algorithm for HEMS: A new approach for the design and diversified performance analysis", Electronics, vol. 8, no. 2, pp. 1-40, 2019.

[15]H. Ling, T. Zhu, W. He, H. C. Luo, Q. Wang and Y. Jiang, "Coverage optimization of sensors under multiple constraints using the improved PSO algorithm", Mathematical Problems in Engineering, vol. 2020, no. 2, pp. 1-10, 2020.

[16]D. Raynaud, S. Gessner and B. Mota, "Andalò di Negro's De compositione astrolabii: A critical edition with English translation and notes", Archive for History of Exact Sciences, vol. 73, no. 6, pp. 551-617, 2019.

[17] M. S. Barker, N. L. Nelson and G. A. Robinson, "Idea formulation for spoken language production: The interface of cognition and language", Journal of the
International Neuropsychological Society, vol. 26, no. 2, pp. 226-240, 2019.

[18] L. Wu and L. Wu, "Research on business English translation framework based on speech recognition and wireless communication", Mobile Information Systems, vol. 2021, no. 4, pp. 1-11, 2021.

[19]F. Huettig and M. J. Pickering, "Literacy advantages beyond reading: Prediction of spoken language", Trends in Cognitive Sciences, vol. 23, no. 6, pp. 464-475, 2019.

[20] Y. Jia, M. Carl and X. Wang, "Post-editing neural machine translation versus phrase-based machine translation for English-Chinese", Machine Translation, vol. 33, no. 1-2, pp. 1-21, 2019.

[21] S. Gu and X. Li, "Optimization of computer-aided English translation teaching based on network teaching platform", Computer-Aided Design and Applications, vol. 19, no. S1, pp. 151-160, 2021.

[22]N. S. Khan, A. Abid and K. Abid, "A novel natural language processing (NLP)-based machine translation model for English to Pakistan sign language translation", Cognitive Computation, vol. 12, no. 2, pp. $1-18,2020$.

[23] H. Wu, "Multimedia interaction-based computer-aided translation technology in applied English teaching", Mobile Information Systems, vol. 2021, no. 5, pp. 1-10, 2021.

Creative Commons Attribution License 4.0 (Attribution 4.0 International, CC BY 4.0)

This article is published under the terms of the Creative Commons Attribution License 4.0

https://creativecommons.org/licenses/by/4.0/deed.en_US 